Article

\title{
Heater Choice, Dampness and Mould Growth in 26 New Zealand Homes: A Study of Propensity for Mould Growth Using Encapsulated Fungal Spores
}

\section{Mikael Boulic 1,*, Robyn Anne Phipps ${ }^{2}$, Malcolm Cunningham ${ }^{3}$, Donald John Cleland ${ }^{\text {, }}$ Pär Fjällström ${ }^{4}$, Keiko Abe ${ }^{5}$ and Philippa Howden-Chapman ${ }^{6}$}

1 School of Engineering and Advanced Technology, Massey University, Manawatu Campus, Palmerston North 4474, New Zealand; E-Mail: d.cleland@massey.ac.nz

2 School of Engineering and Advanced Technology, Massey University, Albany Campus, Auckland 0632, New Zealand; E-Mail: r.a.phipps@massey.ac.nz

3 Building Research Association of New Zealand, Porirua 5381, New Zealand;

E-Mail: malcolmcunninghammjc@gmail.com

4 IVL Swedish Environmental Research Institute, P.O. Box 210 60, SE-100 31 Stockholm, Sweden; E-Mail: par.fjallstrom@ivl.se

5 Institute of Environmental Biology, JDC Corporation, Kanagawa 243-03, Japan;

E-Mail: abekeiko@kamakuranet.ne.jp

6 Department of Public Health, University of Otago, Wellington 6021, New Zealand; E-Mail: philippa.howden-chapman@otago.ac.nz

* Author to whom correspondence should be addressed; E-Mail: m.boulic@massey.ac.nz; Tel.: +64-6-350-5701 (ext. 84149); Fax: +64-6-350-5604.

Academic Editor: George Baird

Received: 27 November 2014 / Accepted: 21 January 2015 / Published: 2 February 2015

Abstract: The relationship between the use of unflued gas heaters (UGH, $N=14)$ and heat pump heaters (HP, $N=12$ ) located in the living rooms, and mould growth on the living room and bedroom walls, of 26 New Zealand (NZ) occupied homes was investigated during winter. Two methods were employed to evaluate the potential of mould growth on walls: (i) measurement of daily hyphal growth rate using a fungal detector (encapsulated fungal spores); and (ii) estimation of fungal contamination based on a four level scale visual inspection. The average wall psychrometric conditions were significantly different between the two heater type groups, in both the living rooms and the bedrooms with the UGH user homes being colder and damper than HP user homes. The UGHs were found to be a 
significant additional source of moisture in the living rooms which dramatically increased the capacity for fungi to grow on wall surfaces. The average daily hyphal growth rates were 4 and 16 times higher in the living rooms and in the bedrooms of the UGH user homes, respectively. Results from both mould detection methods gave good agreement, showing that the use of a fungal detector was an efficient method to predict the potential of mould growth on the inside of the external walls in NZ homes.

Keywords: New Zealand homes; heater usage; psychrometrics; mould growth; fungal detector; visual mould inspection

\section{Introduction}

\subsection{Background}

Houses in New Zealand (NZ) are typically damp and cold [1]. The dampness and low indoor temperature is mainly due to two factors: building insulation deficiency (houses constructed before April 1978 were not subject to regulations requiring insulation) and undersized heating systems (only around $5 \%$ of $\mathrm{NZ}$ dwellings have central heating systems). In winter 2006, when the study was conducted, unflued gas heaters (UGH) were used in $27.7 \%$ of the NZ dwellings [2,3]. While UGHs use in NZ has declined since the study to $15.4 \%$ of the NZ dwellings [4], they are still in common use and hence the study is still relevant. Further, the results are useful for other countries with similar climates, housing stocks and use of UGHs. In NZ, these UGHs are mainly operated on low or medium setting which gives an estimated average heat output of $2.6 \mathrm{~kW}[5]$.

Unflued gas heaters, also called Liquefied Petroleum Gas (LPG) cabinets or portable gas heaters are designed to release combustion gases directly in the indoor environment [6]. In addition, to the chemical pollutants, like nitrogen dioxide [7], released during the combustion process, water vapour is another combustion byproduct which is released at a theoretical rate of $1.6 \mathrm{~kg}$ per $\mathrm{kg}$ of LPG consumed dependent on the proportion of butane and propane in the bottle. Therefore, the use of an UGH increases the room moisture level [8].

Temperature and moisture levels are critical factors for fungal development. Viable spores are always present in dwellings and germination and subsequent hyphal development can occur if the nutrients, temperature and moisture availability are suitable. The mould and their by-products could be harmful for people, particularly if they are immune deficient or asthmatic [9].

\subsection{Methods}

The Housing, Heating and Health Study (HHH Study) was a community trial to investigate the relationship between domestic heaters, indoor environment and occupant's health. Four hundred and nine families with a child with doctor diagnosed asthma (index child), and using an UGH or a portable electric heater as their main heater, were enrolled in this interventional study. Baseline health and environmental parameters were measured in all homes during the first winter/spring season. Before the second winter season, the original heater (UGH or portable electric heater) was replaced by a higher 
capacity and non-indoor polluting heater such as a heat pump heater (HP), for a randomly selected half of the dwellings (Treatment group). The Control group kept using their original heater during the second winter season and received their replacement heater at the end of the study. Health and environmental measurements were repeated in all homes during the second winter [10].

For a subset $(N=26)$ of the HHH Study households, who were operating either an UGH or a HP in the living rooms, the propensity for mould to grow and the indoor climate were investigated using a fungal detector (JDC Corporation, Kanagawa, Japan), and temperature/relative humidity (RH) measurements. Visual inspections of mould growth were carried out to validate the fungal detector predictions. This subset study was undertaken during winter in 26 dwellings in the Hutt Valley, a semi-coastal area that is part of Greater Wellington, New Zealand. The dwellings had been insulated (under floor and roof cavity) before the study started, according to the New Zealand Standard 4218:2004 specifications [11]. Twelve households received a HP (Treatment group) and 14 households were still using their original UGHs (Control group). The level of moisture in homes can be affected by many factors, other than unflued combustion process, like cooking, showering/bathing and drying clothes. However the households were selected with similar other moisture contributors (similar location, similar building construction and insulation level, similar level of occupancy), and it was assumed that the only difference in moisture source will be due to the operation of the heaters. The aim of this study was to investigate the moisture in homes resulting from the use of heater and to determine if a fungal detector could be a useful device to evaluate the suitability of the indoor environment for fungal development during winter time in New Zealand.

For each dwelling, the wall temperature and RH measurements were carried out in the living room and the index child's bedroom, using wall-mounted Hobo ${ }^{\circledR} \mathrm{H} 8$ sensors (Onset Computer Corporation, Bourne, MA, USA). The loggers were attached on the interior lining of an external wall at a consistent height of $1.8 \mathrm{~m}$ above the floor level (B in Figure 1). The loggers were set to monitor the temperature and the RH continuously every 15 min for up to a 41.4 days' period (maximum memory capacity). The logger thickness placed the sensors about $1 \mathrm{~cm}$ away from the wall surface.

In close proximity to this temperature/RH sensor, a fungal detector was located directly on the wall surface (A in Figure 1). The fungal detector consisted of three inclusions of fungal spores; two xerophilic fungi (Eurotium herbariorum and Aspergillus penicilloides) and one hydrophilic fungus (Alternaria alternata) in an encapsulating device (plastic plate, water vapour permeable transparent film and double sided adhesive tape acting as a frame) [12]. Xerophilic fungi grow under relatively dry conditions and hydrophilic fungi need extremely humid conditions to grow. Each fungal inclusion contains $3 \mu \mathrm{L}$ of spore suspension at $10^{6}$ spores per $\mathrm{mL}$ concentration [13]. At the start of exposure, the spores were in a dry state. The fungal detectors were exposed to the living room and bedroom wall climate for an average period of 85 days. At the conclusion of the winter monitoring period, the three fungal inclusions (Aspergillus penicillioides, Eurotium herbariorum and Alternaria alternata) were examined under a microscope and the hyphal lengths were measured.

In addition to the fungal detector assessment method, a visual inspection of mould growth was carried out in the 26 living rooms and bedrooms by the first author. A contamination scale with four graduation levels was used to visually assess the mould level in the living room and in the child's bedroom (M0: "no visible mould", M1: "specks of visible mould", M2: "moderate visible mould patches" and M3: "extensive covered areas"). 


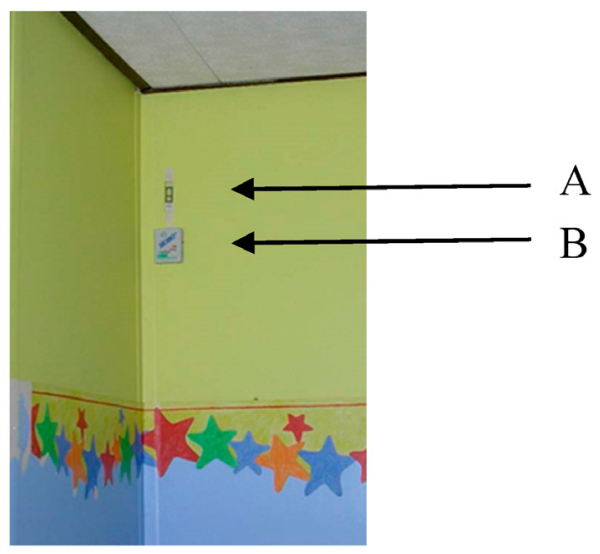

Figure 1. Typical sensor locations on the inside of the external wall in an index child's bedroom (A: fungal detector, B: temperature and relative humidity logger).

\section{Results and Discussion}

\subsection{The Wall Climate}

The temperature/RH loggers operated to full memory capacity (41.4 days). Table 1 shows the average psychrometric conditions in households operating an UGH $(N=14)$ and in households operating a $\mathrm{HP}(N=12)$.

In the living rooms, the wall climates were on average colder $\left(15.2{ }^{\circ} \mathrm{C}\right.$ vs. $\left.17.4{ }^{\circ} \mathrm{C}\right)$ and had higher RH $(63.6 \%$ vs. $53.5 \%)$ in the UGH group than in the HP group. Similar results were found in the bedrooms $\left(13.9^{\circ} \mathrm{C}\right.$ vs. $16.0^{\circ} \mathrm{C}$ and $68.6 \%$ vs. $\left.60.9 \%\right)$ for UGH and HP groups respectively. For both groups, the bedrooms were colder and damper than the living rooms. In the living rooms, Table 1 shows higher humidity ratio in the UGH group than in the HP group $(6.9 \mathrm{~g} / \mathrm{kg} v s .6 .6 \mathrm{~g} / \mathrm{kg})$. This result is consistent with UGH being an additional source of moisture for the living room environment. In the bedrooms, for both groups of households, the humidity ratio was similar $(6.8 \mathrm{~g} / \mathrm{kg} v s .6 .9 \mathrm{~g} / \mathrm{kg})$. With a similar level of humidity ratio, the lower average RH for the HP user group appears to be mainly due to a higher average temperature. This result indicates that the HP seemed to be more effective than the UGH for heating more than one room in the house. The moisture released from the UGH operated in the living rooms appears to have little effect on the bedroom humidity ratio.

Households operating an UGH had a higher RH level than households operating a HP, thus the release of water vapour, during the operation of an $\mathrm{UGH}$, was found to be a significant additional source of moisture for the wall surface in the living rooms. Studies found that operating an UGH at a high setting releases around a half litre of water vapour per hour of use [14,15] with an average vapour pressure increase of $0.01 \mathrm{kPa} / \mathrm{min}[8]$. 
Table 1. Average $[95 \% \mathrm{CI}]$ temperature $(\mathrm{T})$, relative humidity $(\mathrm{RH})$ and humidity ratio in living rooms and bedrooms of households operating either an unflued gas heater or a heat pump heater.

\begin{tabular}{|c|c|c|c|c|c|c|c|}
\hline \multirow[b]{2}{*}{ Heater Use in The Living Room } & \multirow[b]{2}{*}{$N$} & \multicolumn{3}{|c|}{ Living Room } & \multicolumn{3}{|c|}{ Bedroom } \\
\hline & & $\mathbf{T}\left({ }^{\circ} \mathbf{C}\right)$ & RH (\%) & $\begin{array}{c}\text { Humidity Ratio } \\
\text { (g } \mathrm{H}_{2} \mathrm{O} / \mathrm{kg} \text { of Dry Air) }\end{array}$ & $\mathbf{T}\left({ }^{\circ} \mathbf{C}\right)$ & RH (\%) & $\begin{array}{c}\text { Humidity Ratio } \\
\text { (g } \mathrm{H}_{2} \mathrm{O} / \mathrm{kg} \text { of Dry Air) }\end{array}$ \\
\hline \multirow{2}{*}{ Unflued Gas Heater (UGH) } & \multirow{2}{*}{14} & 15.2 & 63.6 & 6.9 & 13.9 & 68.6 & 6.8 \\
\hline & & $14.3-16.2$ & $60.7-66.5$ & $6.6-7.1$ & $12.9-14.8$ & $64.1-73.1$ & $6.4-7.2$ \\
\hline \multirow{2}{*}{ Heat Pump (HP) } & \multirow{2}{*}{12} & 17.4 & 53.5 & 6.6 & 16.0 & 60.9 & 6.9 \\
\hline & & $16.0-18.9$ & $48.9-58.1$ & $6.3-6.9$ & $14.8-17.2$ & $57.6-64.1$ & $6.6-7.2$ \\
\hline
\end{tabular}


Optimal RH is the primary parameter for fungi to grow. When the $\mathrm{RH}$ of the air surrounding the building material is in a steady state condition (equilibrium), this RH is called equilibrium RH (ERH) and is equivalent to the water activity $\left(a_{\mathrm{w}}\right)$ of the building material when expressed as a fraction. A building material in a steady state condition with a surrounding $\mathrm{RH}$ of $70 \%(\mathrm{ERH}=70 \%)$, will have $a_{\mathrm{w}}=0.70$. This $70 \% \mathrm{ERH}$ threshold was chosen in Table 2, as it represents the minimal ERH/ $a_{\mathrm{w}}$ for xerophilic fungi to start growing $[12,16]$ and two of the three fungal inclusions in the fungal detector contained xerophilic fungi (Eurotium herbariorum and Aspergillus penicilloides).

Table 2 shows the percentage of time, in the living rooms and in the bedrooms, with a wall RH above $70 \%$ for both types of heater being operated in the living rooms during the 41.4 days' period.

Table 2 shows that the bedrooms had greater exposure to RH levels above $70 \%$ than the living rooms. The households operating an UGH showed a higher percentage of time in both the living rooms and the bedrooms than the households operating a HP. In fact, the psychrometric conditions were substantially different in the UGH and HP homes which should impact on the capacity for mould to grow on the wall surface.

Table 2. Percentage of time with the wall $\mathrm{RH}$ above $70 \%$ in the living rooms and in the bedrooms.

\begin{tabular}{cccc}
\hline \multirow{2}{*}{ Heater Type Used in the Living Room } & \multirow{N}{*}{} & \multicolumn{2}{c}{ Percentage of Time with RH > 70\% (\%) } \\
\cline { 3 - 4 } & 14 & Living Room & Bedroom \\
\hline Unflued Gas Heater (UGH) & 12 & 9 & 46 \\
Heat Pump (HP) & & 9 & 18 \\
\hline
\end{tabular}

\subsection{Fungal Daily Growth Rate on the Interior Lining of an External Wall Surface}

The 52 fungal detectors (one in each living room and one in each bedroom) were exposed for an average period of 85 days with an exposure range between 62 and 109 days. The exception to this was one dwelling where the fungal detectors stayed for 154 days, due to the householders being unavailable at an earlier time for collection of the slides. Following hyphal measurements under microscope, the daily growth rate outliers were removed from the analysis. The lower outliers were identified as values lower than the value of $(\mathrm{P} 75-((\mathrm{P} 75-\mathrm{P} 25) \times 1.5))$ and the upper outliers were identified as values greater than the value of $(\mathrm{P} 75+((\mathrm{P} 75-\mathrm{P} 25) \times 1.5))$. Wilcoxon's rank tests were applied to test if the daily hyphal growth rate ( $\mu \mathrm{m} /$ day) was different between households operating an UGH and households operating a HP. Figure 2 shows the average daily hyphal growth rate in the living rooms and in the bedrooms.

In the livings rooms, the daily hyphal growth rates for both xerophilic fungi (Aspergillus penicilloides and Eurotium herbariorum) were four times higher in the UGH user group than in the HP user group, however these results were not statistically significant due the small sample size. The daily hyphal growth rate for Alternaria alternata was slightly higher in households operating a HP than in household operating an UGH $(0.90 \mu \mathrm{m} /$ day (HP) vs. $0.77 \mu \mathrm{m} /$ day $(\mathrm{UGH}), p=0.07)$. In the bedrooms, the daily hyphal growth rates for both xerophilic fungi were 7 and 26 times higher in households operating an UGH than in households operating a HP respectively $(p<0.01)$. No significant differences were found for Alternaria alternata between both household groups in the daily hyphal growth rates. 


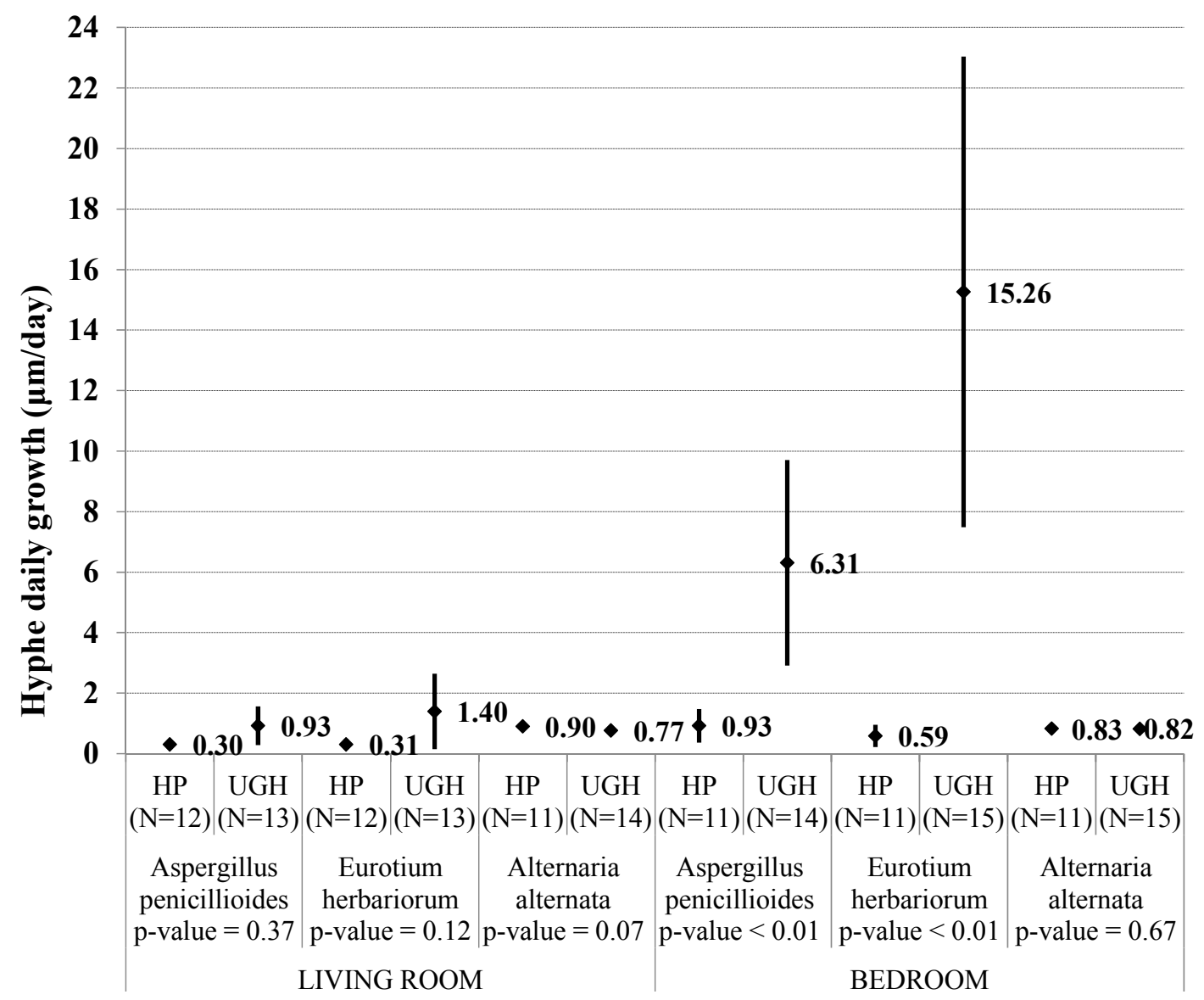

Figure 2. Average daily hyphal growth rate and lower and upper $95 \%$ confidence limit in the living rooms and in the bedrooms (outliers removed).

The climate was found to be more suitable for mould development in the bedrooms than in the living rooms. These results are consistent with the percentage of time that the $\mathrm{RH}$ was above $70 \%$, being twofold higher in the bedrooms than in the living rooms (Table 2). A factor contributing to this difference in bedroom climates was the effect of the heater operated in the living rooms; the HP seems to be more effective than UGH in heating the bedrooms (forced air circulation due to HP fan). Boulic et al. [5] found that UGHs were mainly operated in NZ on low or medium setting which gives an estimated heat output of $2.6 \mathrm{~kW}$. Since most UGH appear to have a nominal heating capacity of $4 \mathrm{~kW}$, that suggests an element of underuse by occupants and as well as a heater capacity issue.

However, the more favourable condition for fungi to grow, in households who operated an UGH, was only true for the two xerophilic fungi Eurotium herbariorum and Aspergillus penicilloides. Consistent with the fact that these two fungi are the first to react to environment changes, they are considered as first colonizers because they can grow under relatively "dry" conditions $\left(a_{\mathrm{w}}>0.70\right)$ whereas hydrophilic fungi like Alternaria alternata need very humid conditions $\left(a_{\mathrm{w}}>0.90\right)$ to start germination $[12,16,17]$. Such conditions were infrequent in all studied houses, even those with UGHs. Abe et al. [18] found higher hyphal growth rate for Eurotium herbariorum in water associated rooms than in other rooms, showing a positive correlation between high moisture source and high hyphal growth rate. However, when comparing Eurotium herbariorum and Alternaria alternata, the same authors found a higher response for Alternaria alternata in water usage area (bathroom) [12]. 


\subsection{Fieldwork Hyphal Development Compared to Laboratory Hyphal Development}

Average temperature and RH were plotted on a climograph (isopleths) for Eurotium herbariorum (Figure 3), and Alternaria alternata (Figure 4). The isopleth for Aspergillus penicilloides is similar to the Eurotium herbariorum isopleth as both fungi have very similar temperature/RH requirements; therefore the Aspergillus penicilloides isopleth is not shown. The temperature/RH values found in the fieldwork were grouped as "UGH living room", "UGH bedroom", "HP living room" and "HP bedroom" and were compared to optimum climate zone for fungal germination which were obtained under constant conditions of temperature/RH in a laboratory. The laboratory data shown in Figure 3 were adapted from published work [13]. The laboratory data shown in Figure 4 were provided by Abe and are unpublished [19].

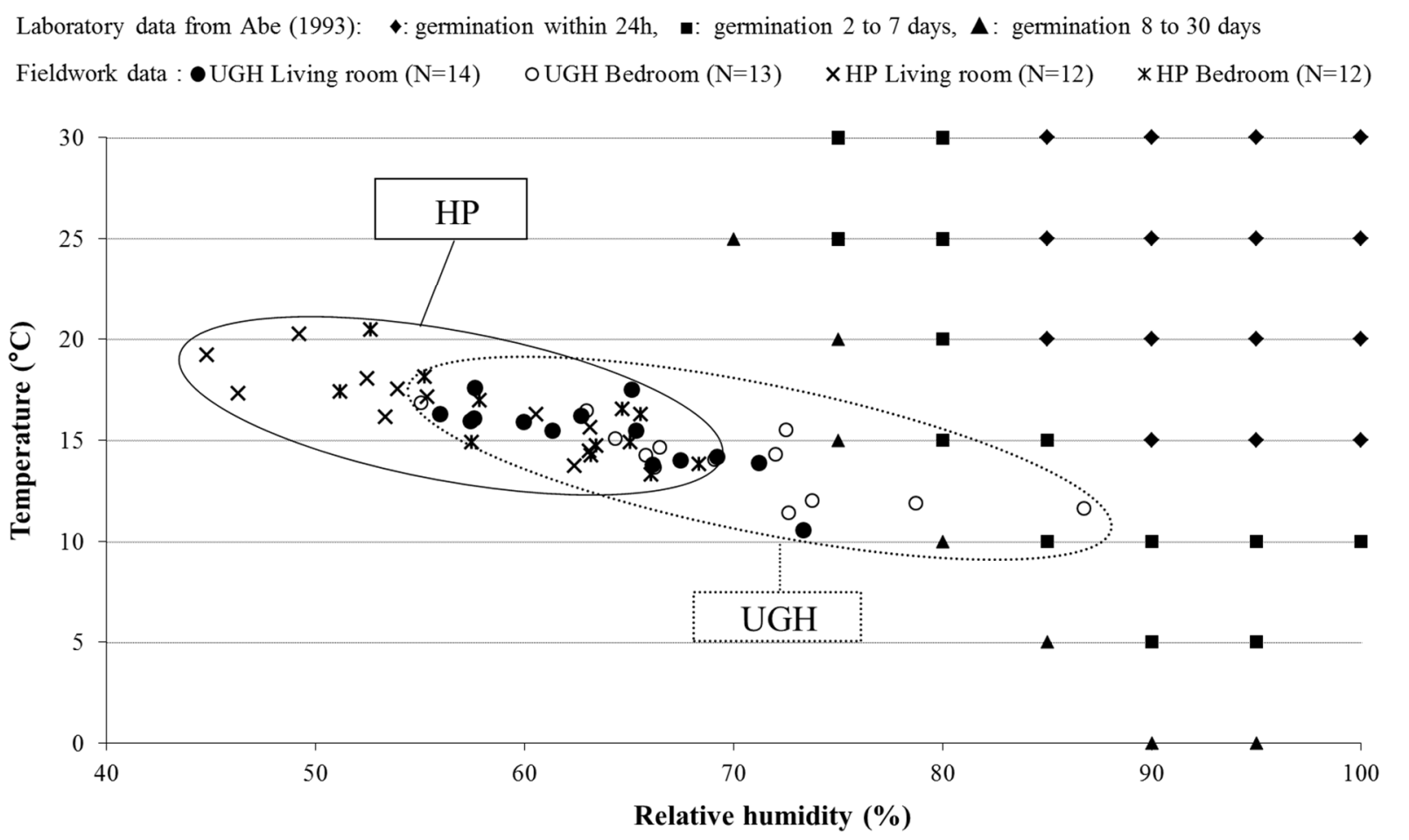

Figure 3. Climograph with germination of Eurotium herbariorum spores; fieldwork data compared to laboratory data (adapted from [13]).

In Figure 3, the 8 to 30 days germination zone (black triangle) starts at $\mathrm{RH}=70 \% / T=25{ }^{\circ} \mathrm{C}$. Figure 3 shows that the average climate in the UGH user group (dashed ellipse) was closer to the germination zone than in the HP user group (plain ellipse). Six bedrooms and two living rooms from the UGH user group had an averaged climate that was either close or within the 8 to 30 days germination zone, whereas no room from the HP user group was within this germination zone. For both groups of households (UGH and HP users), the conditions for mould to grow were more favourable in the bedrooms than in the living rooms.

Figure 4 shows different requirements in terms of temperature/RH for the growth of the hydrophilic fungus Alternaria alternata. In Figure 4, the germination zone (black square) starts at RH $=90 \%$. None of the households from either group was within this germination zone. One bedroom from the UGH user group showed an average $\mathrm{RH}$ of $86.8 \%$ which is close to the germination zone but did not show higher 
hyphal development than the group's average hyphal length. These results are consistent with the very low daily hyphal growth found in both groups for Alternaria alternata (Figure 2).

These results support the previous findings that the daily hyphal growth rates, for both xerophilic fungi (Eurotium herbariorum and Aspergillus penicilloides), were higher in the bedrooms than in the living rooms and also higher in the households operating an UGH than in households operating a HP. The measured temperature/RH values were well below the laboratory germination zone for the hydrophilic fungus Alternaria alternata development $(\mathrm{RH}=90 \%)$, consistent with a low daily hyphal growth rate found for this fungus.

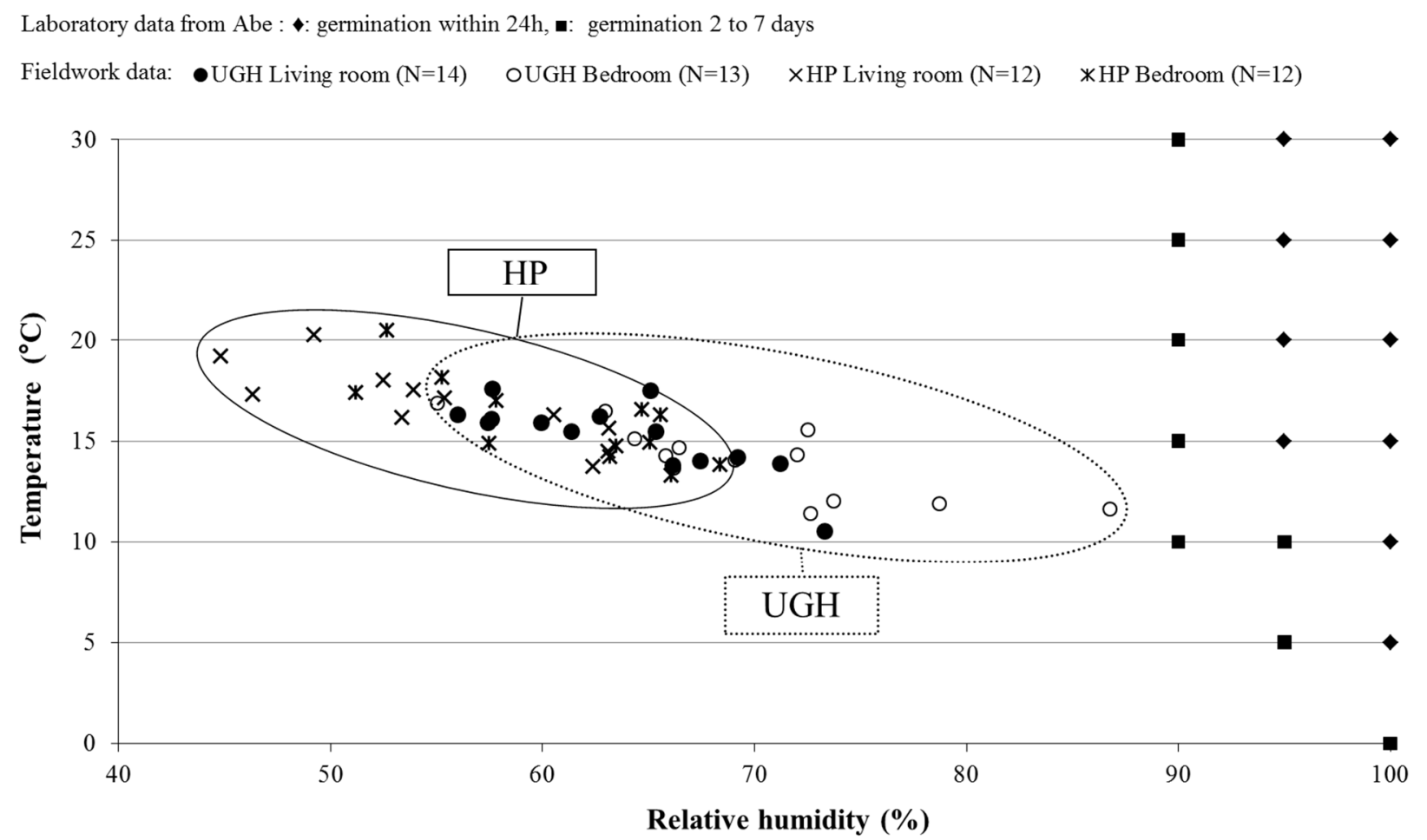

Figure 4. Climograph with germination of Alternaria alternate spores; fieldwork data compared to laboratory data (collected by Abe [19]).

\subsection{Hyphal Development in Response to Favourable Climate Exposure}

The measured daily hyphal growth rate was compared to the time of exposure in favourable psychrometric conditions. This analysis was done using a methodology developed by the Building Research Association of New Zealand [20]. The wall temperature from 0 to $30^{\circ} \mathrm{C}$ and the $\mathrm{RH}$ from $35 \%$ to $100 \%$ were divided into $5{ }^{\circ} \mathrm{C}$ and $5 \% \mathrm{RH}$ ranges, respectively. Next, "bins" were created for each $5{ }^{\circ} \mathrm{C}$ and $5 \% \mathrm{RH}$ increment. For example, the temperature and $\mathrm{RH}$ combination of $0-5{ }^{\circ} \mathrm{C}$ and $35 \%-40 \% \mathrm{RH}$ was the first of the 78 bins. Spearman's rank correlation tests were applied to test the correlation between the time of exposure in the defined bin and the measured daily hyphal growth rate for all three fungi.

Living rooms and bedrooms with a high measured hyphal growth rate (above the 75th percentiles) were selected for the analysis as these living rooms and bedrooms gave the best fungal development in response to the psychrometric conditions. A total of 13 rooms were selected consisting of 9 bedrooms and 4 living rooms in order to compare the Eurotium herbariorum hyphal development to climate exposure. A total of 14 rooms were selected consisting of 10 bedrooms and 4 living rooms to compare 
the Aspergillus penicilloides hyphal development to climate exposure, and a total of 11 rooms were selected consisting of 6 bedrooms and 5 living rooms to compare the Alternaria alternata hyphal development to climate exposure.

For Eurotium herbariorum $(N=13)$, the strongest positive correlation value $\left(R^{2}=0.40, p=0.02\right)$ was detected for the bin $10-15{ }^{\circ} \mathrm{C}$ and $80 \%-85 \%$ RH. For Aspergillus penicilloides $(N=14)$, the strongest positive correlation value $\left(R^{2}=0.28, p=0.05\right)$ was detected for the bin $15-20{ }^{\circ} \mathrm{C}$ and $85 \%-90 \% \mathrm{RH}$. For Alternaria alternata, no significant positive correlation between the measured hyphal growth rate and any climate bin were detected $(p=0.54)$.

Results show that in the rooms where Eurotium herbariorum had the largest hyphal development, the RH was above $80 \%$ for an average of $4.4 \mathrm{~h}$ a day. This result is consistent with a study by Cunningham [20] which found that Eurotium herbariorum needed to be exposed for at least $3.6 \mathrm{~h}$ per day with a RH above $80 \%$ for hyphal development. Similarly, the rooms where Aspergillus penicilloides showed the largest hyphal development had a RH above $85 \%$ for an average of $1.9 \mathrm{~h}$ a day.

Results show that in the rooms where Alternaria alternata had the largest hyphal development, the RH was between $35 \%$ RH and $70 \%$ RH for $77 \%$ of the time. This climate was too dry for this hydrophilic fungus to develop. The climate was suitable for Alternaria alternata (above $90 \% \mathrm{RH}$ ) for only an average of $0.1 \mathrm{~h}$ a day $(0.4 \%$ of the time). This finding supports the lack of correlation found between the daily growth rate and the climate exposure, and was consistent with the low daily hyphal growth rate found for this fungus (Figure 2).

\subsection{Impact of the Heater Choice on the Visible Fungal Level}

Figure 5 shows the percentage of living rooms and bedrooms assessed at each of the four mould indexes in the households either operating an UGH or a HP.

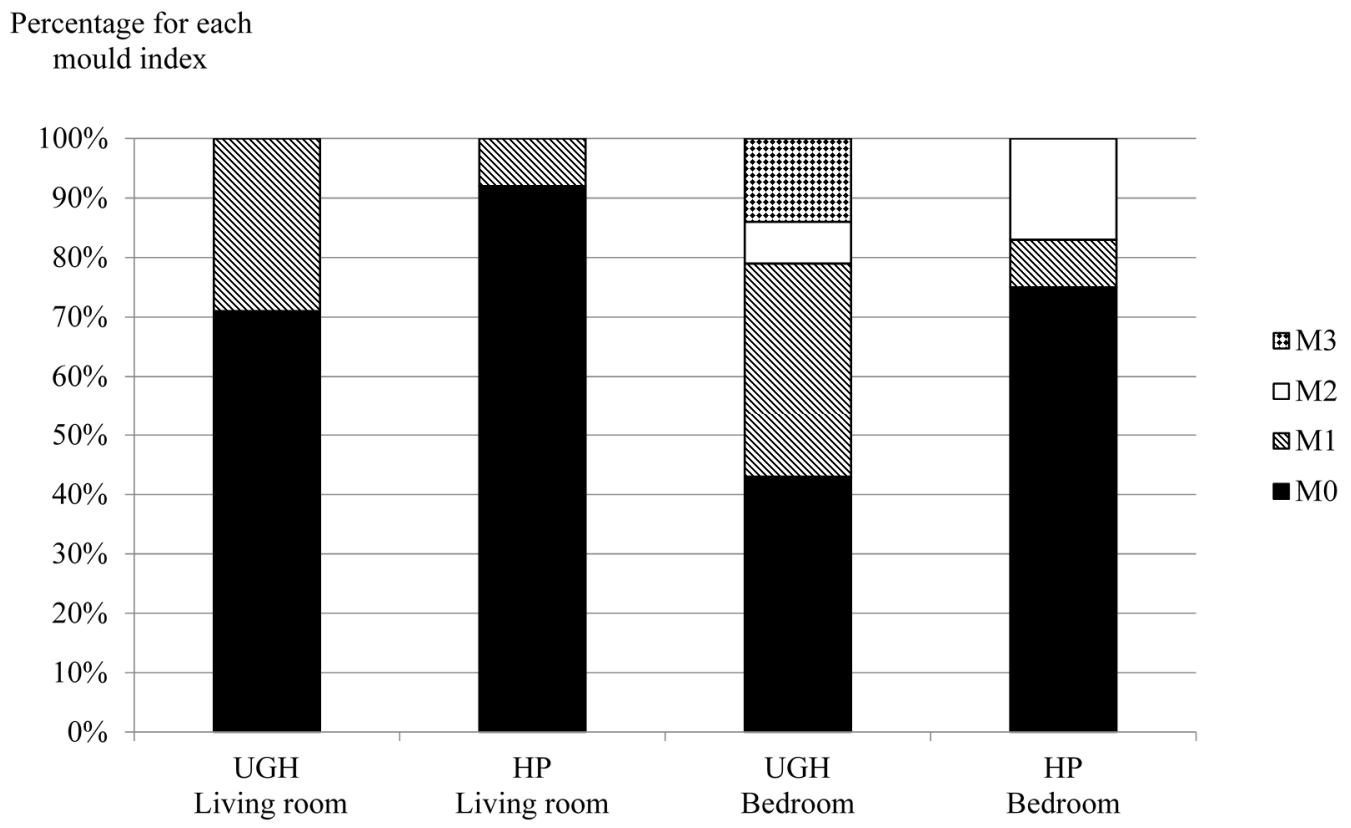

Figure 5. Mould index per heater type (UGH: Unflued Gas Heater or HP: Heat Pump) in the living rooms and in the bedrooms (M0: "no visible mould", M1: "specks of visible mould", M2: "moderate visible mould patches", and M3: "extensive covered areas"). 
Figure 5 shows a higher percentage of houses being assessed with the "M0" mould index (no visible mould) where HP have been operated (92\% vs. $71 \%$ in the living rooms and $75 \% v s .43 \%$ in the bedrooms), compared to the houses where UGH have been operated.

Spearman's rank correlation tests were applied to test the correlation between the visual inspection mould index (M0, M1, M2 or M3) and the measured daily hyphal growth rate for all three fungal inclusions (Aspergillus penicillioides, Eurotium herbariorum and Alternaria alternata).

A positive correlation $\left(R^{2}=0.16, p<0.01\right)$ was found between the visible mould index in living rooms/bedrooms and the measured daily hyphal growth rate for Aspergillus penicilloides. A similar result was found for Eurotium herbariorum $\left(R^{2}=0.16, p<0.01\right)$, however no correlation was found between the visible mould index in living rooms/bedrooms and the measured daily hyphal growth rate for Alternaria alternata ( $p=0.39$ ). In conclusion, for Aspergillus penicillioides and Eurotium herbariorum, we can assume that the more visible mould, the higher the daily hyphal growth will be. Another study reported a positive correlation between a high visual fungal contamination and a high hyphal growth rate for Eurotium herbariorum [18].

A positive correlation was also found between the average wall $\mathrm{RH}$ and the visible mould index $\left(R^{2}=0.16, p<0.01\right)$ and a negative correlation between the average wall temperature and the assessed mould index $\left(R^{2}=(-) 0.14, p<0.01\right)$. In the rooms with a contamination level of M0, M1, M2 and M3, the RH was on average $61.5 \%, 68.2 \%, 70.4 \%$ and $71.5 \%$, respectively. The temperature decrease, correlated to an increase of the visible mould index, is consistent with a RH increase at the same humidity ratio. These results are consistent with a needed threshold of $70 \%$ for xerophilic fungi to start growing.

The visible mould level was found to be higher than the level reported from a self-reported NZ telephone survey [2]. The results showed that the visible mould level and the RH level were positively correlated and that the visible mould level and the temperature were negatively correlated. These findings are consistent with a higher percentage of visible mould detected in households where UGHs were operated. Garrett et al. [21] reported a correlation between evidence of dampness and visible mould. Another study found fungal levels were positively correlated with basement humidity [22] and negative correlation was found between the temperature of the room and the fungal level [23].

A meta-analysis showed strong associations between home dampness and respiratory/allergy effects, but the mechanisms linking the specific causal dampness and the related agents are still not clarified [24]. Mould and other microbiological organisms are probably the link between dampness and adverse health effects [25].

\section{Conclusions}

The households operating an UGH experienced a significantly different wall climate than the households operating a HP. In both the living rooms and the bedrooms, the percentage of time with the RH above 70\% was much higher in homes where UGHs were operated than in homes where HPs were operated.

The fungal detectors were useful to predict the capacity for three species of fungi to grow on the inside surface of an external wall. The results showed that the bedroom climate was more suitable for xerophilic mould growth than the living room climate with a much higher hyphal development found in houses where UGHs were operated. These results were supported with a positive correlation between 
the hyphal development and the time of exposure in the germination psychrometric condition zones. However, it was found that the wall RH levels were too low and therefore not suitable for hydrophilic fungus development like Alternaria alternata.

Results from the visual inspection of mould growth were found to be very consistent with the predictions from the fungal detector method. A positive correlation was found between visible mould index and the measured daily hyphal growth rate for both xerophilic fungi (Aspergillus penicillioides and Eurotium herbariorum). However, it should be noted that the visual inspection is a very subjective method of mould assessment which could be influenced by several confounding factors such as the household mould cleaning, the colour of the wall surface and the age of the building material. In conclusion, the fungal detector method is a good complementary method to the visible inspection.

This intervention study had a positive impact on the wall psychrometrics with reduced water availability for mould to grow. The use of UGH was found to be a significant additional source of moisture in the living rooms. It was apparent that UGH user behaviour had an impact on the capacity to heat more than one room in the house. The households were asked to not modify their behaviour in terms of heater usage and indoor activities. The intervention was on the "intention to treat" rather than a "treatment"; consequently the households did not receive any fuel subsidies to encourage the usage of their heater. A follow up study, to investigate the environmental and health effects when a fuel subsidy assists households to pay for a higher consumption of heating could be interesting.

\section{Acknowledgments}

The hyphal measurements were undertaken thanks to the microscope facilities in the Institute of Veterinary, Animal, and Biomedical Sciences, Massey University, Palmerston North, New Zealand.

Participating families from Hutt Valley and community workers from Waiwhetu Marae, Kokiri Marae and Mid Valley Primary Health Organisation are thanked for their valuable contribution to the study. This study was funded by Health Research Council of New Zealand and Building Research Ltd.

In addition to the named authors, the Housing and Health Research Programme consisted of: Michael Baker, Chris Bullen, Julian Crane, Chris Cunningham, Sarah Free, Julie Gillespie-Bennett, Ralph Chapman, Bob Lloyd, Sarah Nicholls, Nevil Pierse, David Shields, Helen Viggers, Kristin Wickens and Alistair Woodward.

\section{Author Contributions}

The paper is based on Mikael Boulic's PhD research work. Robyn Phipps, Malcolm Cunningham and Don Cleland provided supervision and guidance over this research work. All three supervisors reviewed the paper. Pär Fjällström assisted with the study design, the data collection and the review of the paper. Keiko Abe assisted with the data analysis of the fungal detectors and the review of the paper. This research work was a sub study of the Housing, Heating and Health Study which was led by Philippa Howden-Chapman who assisted with the study design and the review of the paper. In addition to the named authors, researchers from the Housing and Health Research Programme reviewed the paper. 


\section{Conflicts of Interest}

The authors declare no conflict of interest.

\section{References}

1. Isaacs, N.; Camilleri, M.; Pollard, A. Housing, Health and Energy. In Housing and Health: Research, Policy and Innovation; Howden Chapman, P., Carroll, P., Eds.; Steele Roberts: Wellington, New Zealand, 2004.

2. Howden-Chapman, P.; Saville-Smith, K.; Crane, J.; Wilson, N. Risk factors for mold in housing: A national survey. Indoor Air 2005, 15, 469-476.

3. Wilton, E. Warm Homes Technical Report: Home Heating Methods and Fuels in New Zealand; Ministry for the Environment: Wellington, New Zealand, 2005.

4. Statistics New Zealand. New Zealand 2013 Census QuickStats about Housing. Available online: http:/www.stats.govt.nz/Census/2013-census/profile-and-summary-reports/quickstats-about-housing/ heating-fuels.aspx (accessed on 21 November 2014).

5. Boulic, M.; Fjällström, P.; Phipps, R.; Cunningham, M.; Cleland, D.; Howden Chapman, P.; Chapman, R.; Viggers, H. Cold Homes in New Zealand-Heater Capacity or Low Heater Use? In Proceedings of the SB07 NZ Sustainable Building Conference, Auckland, New Zealand, 14-16 November 2007.

6. Francisco, P.W.; Gordon, J.R.; Rose, B. Measured concentrations of combustion gases from the use of unvented gas fireplaces. Indoor Air 2010, 20, 370-379.

7. Gillespie-Bennett, J.; Pierse, N.; Wickens, K.; Crane, J.; Nicholls, S.; Shields, D.; Boulic, M.; Viggers, H.; Baker, M.; Woodward, A.; et al. Sources of nitrogen dioxide $\left(\mathrm{NO}_{2}\right)$ in New Zealand homes: Findings from a community randomized controlled trial of heater substitutions. Indoor Air 2008, 18, 521-528.

8. Francisco, P.W.; Gordon, J.R.; Rose, W.B. Indoor moisture in 30 homes using unvented gas fireplaces. ASHRAE Trans. 2009, 115, 914-923.

9. Mendell, M.J.; Mirer, A.G.; Cheung, K.; Douwes, J.; Sigsgaard, T.; Bonlokke, J.; Meyer, H.W.; Hirvonen, M.R.; Roponen, M. Chapter 4: Health Effects Associated with Dampness and Mould. Dampness and Mould: WHO Guidelines for Indoor Air Quality; World Health Organization—Regional Office for Europe: Copenhagen, Denmark, 2009.

10. Howden-Chapman, P.; Pierse, N.; Nicholls, S.; Gillespie-Bennett, J.; Viggers, H.; Cunningham, M.; Phipps, R.; Boulic, M.; Fjällström, P.; Free, S.; et al. Effects of improved home heating on asthma in community dwelling children: Randomised controlled trial. Br. Med. J. 2008, 337, 852-855.

11. NZS 4218:2004 Energy Efficiency-Small Building Envelope; New Zealand Standard: Wellington, New Zealand, 2004.

12. Abe, K. Assessment of home environments with a fungal index using hydrophilic and xerophilic fungi as biologic sensors. Indoor Air 2012, 22, 173-185.

13. Abe, K. A method for numerical characterization of indoor climates by a biosensor using a xerophilic fungus. Indoor Air 1993, 3, 344-348. 
14. Camilleri, M.; Isaacs, N.; Pollard, A.; Stoecklein, A.; Tries, J.; Jamieson, T.; Pool, F.; Rossouw, P. Energy Use in New Zealand Households: Report on the Year 4 Analysis for the Household Energy End-Use Project (HEEP); Study Report SR 98; BRANZ: Porirua, New Zealand, 2000.

15. Tenwolde, A.; Pilon, C.L. The Effect of Indoor Humidity on Water Vapor Release in Homes. In Proceedings of Thermal Performance of the Exterior Envelopes of Whole Buildings X Conference, Clearwater Beach, FL, USA, 2-7 December 2007.

16. Flannigan, B.; Miller, J.D. Microbial Growth in Indoor Environments. In Microorganisms in Home and Indoor Work Environments: Diversity, Health Impacts, Investigation and Control, 2nd ed.; Flannigan, B., Samson, R.A., Miller, J.D., Eds.; Taylor \& Francis: London, UK, 2011.

17. Darby, J.A.; Caddick, L.P. Review of Grain Harvest Bag Technology under Australian Conditions. A Comprehensive Analysis and Field Evaluation of Harvest Bag Technology: Incorporating a Review of Hermetic and Temporary Storage, Control of Insects and Fungi, and Preservation of Grain Quality, under Typical Australian Storage and Handling Conditions; Technical Report—No. 105; CSIRO Entomology: Clayton South, Australia, 2007.

18. Abe, K.; Nagao, Y.; Nakada, T.; Sakuma, S. Assessment of indoor climate in an apartment by use of a fungal index. Appl. Environ. Microbiol. 1996, 62, 959-963.

19. Abe, K. Institute of Environmental Biology, JDC Corporation, Kanagawa, Japan. Personal communication, 2006.

20. Cunningham, M.J. Final Report on an Alternative Solution to NZBC E3 Field Validation and Model Modification; BRANZ: Porirua, New Zealand, 2001.

21. Garrett, M.H.; Rayment, P.R.; Hooper, M.A.; Abramson, M.J. Indoor airborne fungal spores, house dampness and associations with environmental factors and respiratory health in children. Clin. Exp. Allergy 1998, 28, 459-467.

22. Dekoster, J.A.; Thorne, P.S. Bioaerosol concentrations in noncomplaint, complaint, and intervention homes in the midwest. Am. Ind. Hyg. Assoc. J. 1995, 56, 573-580.

23. O’Connor, G.T.; Walter, M.; Mitchell, H.; Kattan, M.; Morgan, W.J.; Gruchalla, R.S.; Pongracic, J.A.; Smartt, E.; Stout, J.W.; Evans, R. Airborne fungi in the homes of children with asthma in low-income urban communities: The inner-city asthma study. J. Allergy Clin. Immunol. 2004, 114, 599-606.

24. Mendell, M.J.; Mirer, A.G.; Cheung, K.; Tong, M.; Douwes, J. Respiratory and allergic health effects of dampness, mold, and dampness-Related agents: A review of the epidemiologic evidence. Environ. Health Perspect. 2011, 119, 748-756.

25. Fisk, W.J.; Lei-Gomez, Q.; Mendell, M.J. Meta-analyses of the associations of respiratory health effects with dampness and mold in homes. Indoor Air 2007, 17, 284-296.

(C) 2015 by the authors; licensee MDPI, Basel, Switzerland. This article is an open access article distributed under the terms and conditions of the Creative Commons Attribution license (http://creativecommons.org/licenses/by/4.0/). 